\title{
GRIYA HABILITATIF PENANGANAN ANAK BERKEBUTUHAN KHUSUS (GRAHA PEGASUS) DI KECAMATAN KARANGANOM KABUPATEN KLATEN
}

\author{
Arif Pristianto', Farid Rahman $^{2}$, Rita Setiyaningsih ${ }^{3}$ \\ Program Studi Fisioterapi, Fakultas Ilmu Kesehatan \\ Universitas Muhammadiyah Surakarta \\ Email : arif.pristianto@ums.ac.id, farid.rahman@ums.ac.id, ritasetiya2608@gmail.com
}

\begin{abstract}
ABSTRAK
Setiap anak yang terlahir di dunia ini dapat beresiko mengalami abnormalitas sehingga memerlukan penanganan khusus. Deteksi dini bagi anak berkebutuhan khusus dengan berbagai instrumen pemeriksaan yang ada menjadi cara terbaik agar kondisi anak dapat tertangani sejak awal. Selain itu pemberian terapi sejak awal dapat menunjang aktivitas sehari-hari seperti mengasah motorik kasar dan motorik halus. Di Indonesia sendiri terapi latihan untuk anak berkebutuhan khusus yang dilakukan fisioterapis masih belum banyak diketahui masyarakat apalagi mereka yang tingkat ekonomi dan pendidikannya rendah. Beberapa orang tua bahkan hanya membiarkan anaknya tergeletak di rumah karena ketidaktahuannya dan biaya pengobatan. Bahkan beberapa dari mereka ada yang cenderung menutupi informasi tentang kondisi anaknya. Maka dari itu kami memberikan solusi yaitu dengan mendirikan Griya Habilitatif Penanganan Anak Berkebutuhan Khusus (Graha Pegasus). Program Graha Pegasus ini merupakan wadah untuk menampung anak berkebutuhan khusus dengan kondisi ekonomi keluarga menengah ke bawah di Kecamatan Karanganom, Kabupaten Klaten untuk mendapatkan terapi secara gratis dan memberikan edukasi kepada orang tua maupun ke luarga tentang bagaimana menangani anak berkebutuhan khusus. Tujuan dari terapi itu sendiri adalah pengembangan gerak dan fungsi tubuh anak berkebutuhan khusus agar mereka dapat melakukan aktivitas secara mandiri dan tidak bergantung kepada orangtuanya.
\end{abstract}

Kata kunci : Griya Habilitatif, Anak Berkebutuhan Khusus

\begin{abstract}
Every child born in this world can be at risk of having an abnormality that requires special treatment. Early detection for children with special needs with a variety of existing examination instruments is the best way to handled child condition from beginning. In addition it can be done by therapy to support daily activities such as sharpening gross motor and fine motor. In Indonesia, therapy for children with special needs done by physiotherapist is still not much known to the public especially those whose economy and education are low. Some parents even just let their children lay at home because of their ignorance and medical expenses. Some of them even tend to covering about their child's condition. Therefore we provide a solution that is to establish Griya Habilitatif Penanganan Anak Berkebutuhan Khusus (Graha Pegasus). Graha Pegasus program is a place to accommodate children with special needs with the economic condition of low-income families in Karanganom District, Klaten regency to get therapy for free and provide education to parents and families about how to handle children with special needs. The purpose of therapy itself is the development of motion and body functions of children with special needs so that they can perform activities independently and do not depend on their parents.
\end{abstract}

Keywords: Griya habilitatif, children with special needs

DOI : https://doi.org/10.36341/jpm.v1i3.519 $260 \quad$ Some rights reserved BY-NC-SA 4.0 International License




\section{PENDAHULUAN}

Ketidaksempurnaan bukanlah pantangan untuk memperjuangkan dan meneruskan hidup. Banyak penyandang cacat yang tetap mampu berkreasi bahkan menciptakan sebuah penghargaan yangmana orang-orang normal tidak mampu melakukannya. Berdasarkan Undang-Undang No. 8 tahun 2016 tentang penyandang cacat pada pasal 1 ayat 1 disebutkan bahwa penyandang cacat adalah setiap orang yang mempunyai kelainan fisik dan atau mental, yang dapat mengganggu atau merupakan rintangan dan hambatan baginya untuk melakukan kegiatan secara layak. Penyandang cacat terdiri dari penyandang cacat fisik, penyandang cacat mental, dan penyandang cacat fisik dan mental. Meskipun demikian, dalam pasal 5 dan pasal 7 menegaskan bahwa penyandang cacat merupakan bagian masyarakat Indonesia yang juga memiliki kedudukan, hak, kewajiban, serta peran yang sama. Cacat fisik maupun mental bukan kriteria yang membuat mereka menjadi kaum yang terisolasi. Apabila kita telusuri lebih dalam banyak penyandang cacat yang mampu menjadi figur bahkan motivator. Kecacatan bukan suatu alasan untuk menyerah, tidak produktif, tidak berkreasi, dan tidak mandiri. Untuk itulah pentingnya motivasi, edukasi, dan habilitasi kepada para penyandang cacat fisik untuk terus semangat hidup dalam diri mereka.

Berdasarkan wawancara dan pengamatan kami didapatkan bahwa di Kecamatan Karanganom Kabupaten Klaten terdapat 8 anak yang mengalami gangguan fisik/disabilitas. Hasil pemeriksaan pada 8 anak yang mengalami disabilitas ini, didapati diagnosa berupa 7 anak Cerebral Palsy (CP) spastic/kaku dan ataxia (bermasalah dengan keseimbangan) serta 1 anak Down Syndrome (DS). Cerebral Palsy (CP) merupakan kondisi gangguan motorik pada anak yang disebabkan kerusakan otak pada masa sebelum, selama, maupun setelah dilahirkan (Miller \& Bachrach, 2017). Hal umum yang dijumpai pada anak CP antara lain gangguan koordinasi, gangguan keseimbangan, dan pola gerak yang abnormal. Meskipun tidak bersifat progresif, tapi gangguan gerak dan postural yang muncul akan menyebabkan gangguan pada ADL yang berarti buruknya kemandirian anak bahkan ketika sudah beranjak dewasa. Perkembangan motorik berkaitan dengan pemeriksaan perkembangan anak, perilaku motorik berintegrasi dengan psikologi, serta berhubungan erat dengan kognitif dan emosi (Adolph \& Berger, 2005). Down syndrome (DS) sendiri merupakan kelainan genetik pada bayi dimana adanya trisomi pada kromosom 21 (Lal et al., 2015). Kondisi ini menyebabkan adanya permasalahan berupa tonus otot yang lebih lemah dibanding anak-anak normal yang tentunya akan menggangu perkembangan motorik serta adanya gangguan mental pada anak dengan kondisi DS. Selain itu, pada anak DS juga dapat dijumpai kelainan kerja jantung dan sistem pernapasan sehingga mengganggu aktifitas fisik.

Temuan di desa binaan Karanganom terdapat permasalahan yang signifikan yang terjadi pada Anak-anak Berkebutuhan Khusus (ABK) yaitu pemeriksaan reflek primitif. Reflek plantar grasp pada bayi yang baru lahir digunakan untuk mendeteksi spastisitas. Reflek grasp pada tangan maupun kaki menunjukkan kontrol yang buruk pada area motorik, tidak adanya reflek moro pada proses persalinan hingga kelahiran awal bayi mengidentifikasikan keadaan yang berbahaya (Futagi et al., 2012). Permasalahan yang mencolok di sini yaitu masih dominannya reflek primitif yaitu grasp pada tangan yang belum terintegrasi. Reflek ini berupa tangan menggenggam saat aktivitas sehari-hari karena kurang optimalnya kematangan pada otak. Padahal reflek grasp yang terintegrasi dibutuhkan untuk persiapan merangkak dan pengenalan sensorik yaitu touch. Reflek primitif grasp tangan yang masih dominan harus segera ditangani agar tidak menyebabkan keterlambatan pada pertumbuhan anak. Pada anak berkebutuhan khusus yang masih dominan reflek grasp mayoritas belum bisa merangkak dan keseimbangan saat duduk masih kurang stabil.

Selama ini pihak keluarga tidak pernah mendapatkan atau mendatangi rumah sakit/klinik untuk memperoleh pelayanan kesehatan. Hal ini dikarenakan orangtua sibuk bekerja sebagai 
buruh harian/buruh tani. Kesalahan informasi bahwa keterlambatan berjalan yang dianggap sebagai hal biasa sehingga membuat pertolongan atau penanganan cenderung terlambat. Kepedulian warga sekitar penderita juga belum lama tersentuh, Baru 6 bulan terakhir pihak kecamatan berinisiasi membangun pusat inklusi (inklusi center) Bhakti Negeri sebagai tempat untuk menampung para Anak Berkebutuhan Khusus (ABK). Namun tenaga kesehatan yang khusus menangani terapi bagi anak ABK ini belum ada. Selama 6 bulan ini tenaganya diisi oleh relawan yang belum pernah mendapatkan pendidikan formal tentang terapi bagi ABK. Kondisi anak yang didapati di sana berupa lumpuh, kaku, dan kelemahan pada otot postural.

Keterbatasan ekonomi serta jauhnya tempat tinggal dari fasilitas kesehatan yang memadai, membuat mereka tidak melakukan pemeriksaan dan terapi dini terhadap kelainan yang diderita, sehingga banyak ditemukan anak yang keadaannya sudah memburuk. Problem fisik yang ditemukan berdasarkan pemeriksaan fisioterapi diantaranya; spastik, kontraktur, hipotonus, paralise otot, gangguan respirasi/pulmonal. Apabila unsur tersebut terganggu, akan menghambat kegiatan fungsional tubuh baik tangan maupun kaki dan kemampuan mobilisasi. Selain itu terdapat problem rehabilitasi diantaranya; tidak dapat berguling, merangkak, duduk, berdiri, dan jalan, serta mengalami gangguan ADL (Activity of Daily Living).

Melihat pentingnya penanganan dan habilitasi terhadap Functional Problems Oriented yang banyak dialami oleh anak-anak disabilitas di Inklusi Center Bhakti Negeri Kecamatan Karanganom, Kabupaten Klaten maka kami membuat program sebagai upaya untuk membantu Inklusi Center Bhakti Negeri dalam memfasilitasi anak-anak.

\section{METODE}

Pengabdian ini dilakukan pada bulan Agustus-September 2017 bertempat di Aula Kantor Kecamatan Karanganom, Klaten dan bekerja sama dengan tim inklusi center serta melibatkan tim study club Fisiopedi UMS. Hal-hal yang dilakukan selama program ini berlangsung antara lain:

1. Memberikan penjelasan dan informasi mengenai kondisi Cerebral Palsy, Down Syndrome, dan Delay Development yang dialami anak-anak kepada orang tua meliputi penyebab, terapi, dan edukasi.

2. Memberikan motivasi kepada anak-anak, orang tua, dan anggota keluarga melalui tayangan film pendek atau video yang memiliki makna bahwa anak-anak berkebutuhan khusus mampu dan bisa hidup layaknya orang normal biasa.

3. Menimbulkan rasa percaya diri pada anak - anak dengan cara memaksimalkan interaksi terhadap teman-teman dengan metode permainan yang sesuai misalnya bernyanyi bersama.

4. Mendesain orthose tangan yang terjangkau dan murah agar anak-anak yang mengalami Cerebral Palsy dengan pola flacid maupun spastik pada tangannya dapat terfasilitasi. Alat ini terbuat dari kayu triplek sebagai alas dengan perekat dari kain untuk merekatkan jarijarinya. Prosedur pembuatannya adalah; mencetak ukuran triplek sesuai lebar tangan anak tersebut dengan menggambar atau mengeblat bentuk tangan terlebih dahulu pada kertas, memotong triplek sesuai ukuran lebar tangan masing-masing anak, mengikis pinggiran triplek agar membentuk dan menyerupai tangan, menempelkan kain perekat pada kelima jari dan sisi dorsal tangan sebagai sabuk agar orthose dapat terpasang. Kemudian cara pemakain alat ini memasangkan sabuk-sabuk perekat tersebut pada tempatnya dengan posisi tangan pronasi. 
5. Keluarga mampu melakukan terapi latihan sesering mungkin kepada anaknya dengan terapi latihan yang sudah diedukasi. Edukasi yang diajarkan berupa terapi latihan dasar yang mudah ditiru dan aman dilakukan, misalnya; pasive movement pada ekstremitas atas dan bawah, mobilisasi thorak. Selain itu, dengan kegiatan ini juga akan menciptakan interaksi yang baik antara anak dengan orang tua maupun keluarga.

6. Penderita mampu melakukan kegiatan ADL meskipun minim setidaknya dapat mandiri untuk dirinya sendiri misalnya dengan cara memfasilitasi merangkak apabila anak belum dapat merangkak agar dapat berpindah tempat tanpa bantuan orang lain sehingga aktivitasnya secara perlahan akan terfasilitasi.

\section{HASIL DAN PEMBAHASAN}

Setelah lima minggu program ini berjalan maka didapatkan hasil berupa peningkatan aktivitas fungsional seperti berguling, duduk, merangkak, dan berdiri meskipun tidak terlalu signifikan. Setidaknya hal ini dapat menghambat deformitas dan kontraktur pada otot ekstremitas. Kontraktur dan deformitas sendiri merupakan perubahan struktur pada jaringan keras (tulang) dan jaringan lunak (otot, tendon, ligamen) yang dapat menjadi permanen sehingga akan menghambat aktifitas dan kemampuan fungsional dari ABK (Hinchcliffe, 2007). Program terapi selain meningkatkan kemampuan kerja dari ektremitas atas dan bawah juga menyasar pada perbaikan tonus otot postural. Perbaikan pada bagian ini akan membantu optimalisasi kerja dari keempat ekstremitas serta meningkatkan keseimbangan (Kisner \& Colby, 2012). Beberapa metode terapi yang dikombinasikan antara lain Bobath concept, PNF (Propioceptive Neuromuscular Facilitation), serta Neuro Stucture terbukti berhasil dalam memperbaiki pola gerak dan postur bagi anak ABK.

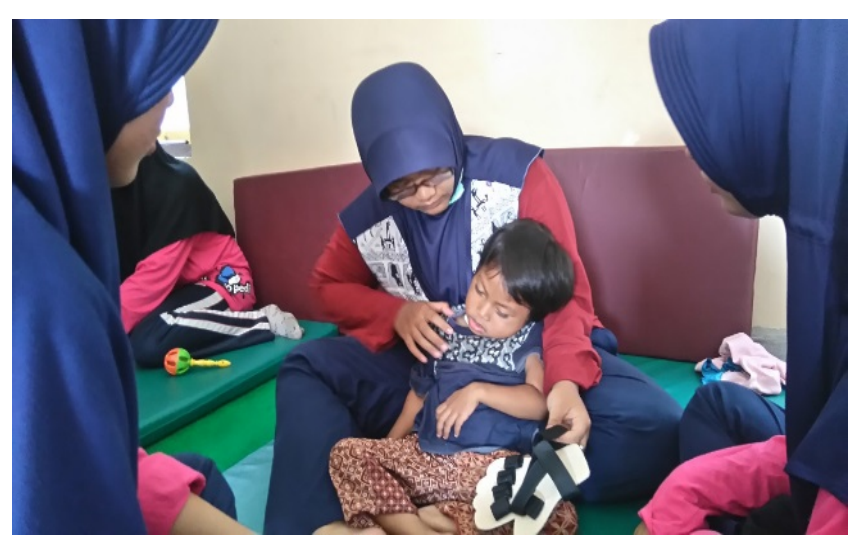

Gambar 1. Implementasi Program Graha Pegasus 


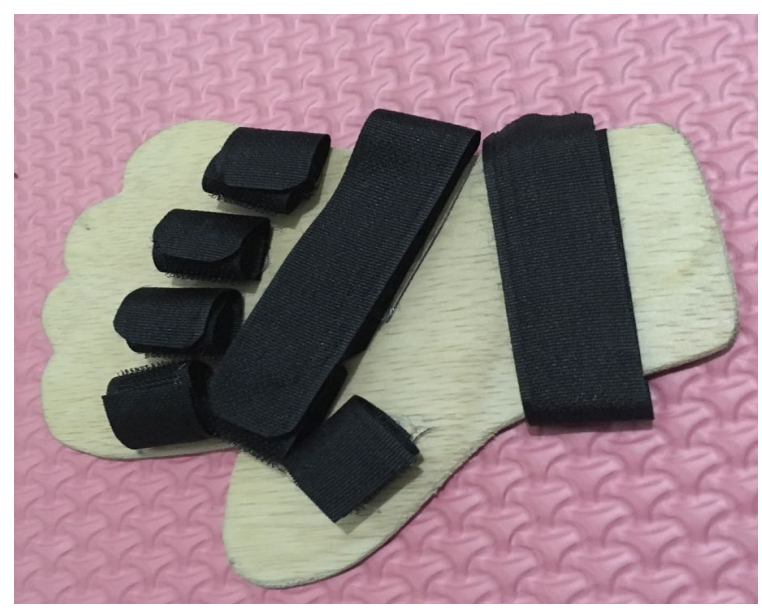

Gambar 2. Desain Splint Sederhana

\section{KESIMPULAN}

Anak-anak berkebutuhan khusus di Kecamatan Karanganom diagnosisnya beraneka ragam dan perlu penanganan yang intensif. Kebanyakan dari mereka tidak berobat/terapi dikarenakan keadaan ekonomi, jauhnya sarana prasarana, dan kurangnya pengetahuan tentang kondisi anaknya sekarang. Mereka beranggapan bahwa anaknya anaknya hanya terlambat dalam perkembangannya saja.

Diharapkan orang tua lebih memperhatikan kesehatan, nutrisi yang diberikan pada anaknya. Serta cek kesehatan berkala di puskesmas terdekat pada saat hamil, melahirkan, maupun bagi anak setelah dilahirkan. Karena anak berkebutuhan khusus dapat terdeteksi pada masa tumbuh kembang. Selain itu, peran aktif dari semua elemen seperti dinas kesehatan, profesi kesehatan, pemerintah setempat maupun daerah, dan lembaga khusus bagi anak berkebutuhan khusus juga sangat diperlukan. Tidak menutup kemungkinan untuk pengaplikasian program ini bagi daerah lain.

\section{UCAPAN TERIMA KASIH}

Kegiatan pengabdian ini merupakan bentuk nyata aplikasi keilmuan fisioterapi khususnya pada anak berkebutuhan khusus. Selain itu, kegiatan ini juga menjadi wadah pembelajaran bagi mahasiswa yang tergabung dalam study club Fisiopedi di UMS.

\section{DAFTAR PUSTAKA}

[1] Adolph, K.E. \& Berger, S.E. (2005). Physical and Motor Development. Developmental Science: $\begin{array}{llllll}\text { An } & \text { Advanced } & \text { Texbook. } & \text { Diakses } & 5 & \text { Oktober }\end{array}$ http://www.psych.nyu.edu/adolph/publications/2005AdolphBergerPhysicalMotorDevelopment Chapter.pdf

[2] Futagi et al. (2012). The Grasp Reflex and Moro Reflex in Infants:_Hierarchy of Primitive Reflex Responses. International Journal of Pediatrics. 
[3] Hinchcliffe, A. (2007). Children with Cerebral Palsy (Second). New Delhi: Sage Publication.

[4] Kisner, C. \& Colby, L.A. (2012). Therapeutic Exercise, Foundations and Techniques (6 ${ }^{\text {th }}$ Edition). Philadelphia: Davis Company.

[5] Lal, C., White, D.R., Joseph, J.E., vanBakergem, K., \& LaRosa, A. (2015). Sleep-Disordered Breathing in Down Syndrome. American College of Chest Physicians Journal, vol. 147, no. 2.

[6] Miller, B.F. \& Bachrach, S.J. (2017). Cerebral Palsy: A Complete Guide for Caregiving, (3 ${ }^{\text {rd }}$ edition). Maryland: Johns Hopkins University Press. 